\title{
Recommender System for Sport Videos Based on User Audiovisual Consumption
}

\author{
Faustino Sánchez, María Alduán, Federico Álvarez, \\ and Orlando Báez
}

\begin{abstract}
This paper describes a recommender system for sport videos, transmitted over the Internet and/or broadcast, in the context of large-scale events, which has been tested for the Olympic Games. The recommender is based on audiovisual consumption and does not depend on the number of users, running only on the client side. This avoids the concurrence, computation and privacy problems of central server approaches in scenarios with a large number of users, such as the Olympic Games.

The system has been designed to take advantage of the information available in the videos, which is used along with the implicit information of the user and the modeling of his/her audiovisual content consumption. The system is thus transparent to the user, who does not need to take any specific action.

Another important characteristic is that the system can produce recommendations for both live and recorded events.

Testing has showed advantages compared to previous systems, as will be shown in the results.
\end{abstract}

Index Terms-Audiovisual consumption, hidden Markov model (HMM), recommender system, sport videos.

\section{INTRODUCTION}

I $\mathrm{N}$ this paper, we propose a recommender system for sport videos which will be applied in an Olympic Games scenario using hybrid access from the Internet or broadcast TV.

This scenario poses some restrictions due to the large audience. Saturation (too many users) and computational problems are likely to appear when the recommendation processes run on the server side. For this reason, classic recommendation techniques such as collaborative filtering [1] cannot be used, and new content-based algorithms have been designed. These new algorithms have the advantage of being implemented on the client side, since only general metadata about distributed video content and information about the own user are needed. Transforming a classic centralized recommender system into a grid computing system by taking advantage of the capabilities of the user's browser boosts the system's performance and allows for millions of concurrent users

Another important restriction is to not interfere with user experience. Following this constraint, the recommendations are generated based on the audiovisual consumption of the user: the process is transparent to the viewer. Only the final recommendation list is presented at all times.

The main advantage of using Olympic Games videos is that they are exhaustively annotated, with complete information about video content characteristics. This information is broadcast in the videos in XML format, which follows the SportsML standard [2]. All the attributes which are important for the users have previously been defined. The system extracts the information needed to take the values of the defined attributes from the SportsML file.

The audiovisual consumption of each user is modeled considering these attributes and both particular and general user consumption trends. Multiple mathematical processes are used for that purpose: interpolation, smoothing, quantification, hidden Markov models (HMM) and Bayesian inference.

First, the importance of each attribute for the user and his/her preferred values are obtained. Taking into account the user information and the content information extracted, a final rating is generated. The best customized ratings are recommended to each user.

The system has been implemented in client-side Web languages as HTML and Javascript. This allows for the application of the system to a hybrid Web-TV environment, and the use of HBBTV technologies [3].

The remainder of this paper is organized as follows. Section II describes related work. Section III explains our approach and the attribute definition. Section IV describes the architecture of the system. Sections V-VII explain the consumption modeling and the recommendation processes. Section VIII presents the tests and experiments for the validation of our system. Finally, Section IX states both the future work and the conclusions.

\section{RELATED WORK}

The most usual techniques for the generation of video recommendations are based on taking each video as a general item, without analyzing content characteristics. Following this approach, social techniques such as collaborative filtering [4] can be applied [5]. They are efficient and easy to apply. Another common technique is the use of standardized ontologies [6], [7] which allows for the calculation of similarities using metrics as the Pearson correlation coefficient or the cosine measurement [8]. 
However, the proposed video recommender system has to be adapted to a scenario with the aforementioned concurrence restrictions. These restrictions require that the recommender system runs only on the client side, therefore collaborative filtering or other social techniques cannot be used.

In this context, only content-based techniques can be used. A new algorithm based on the Winnow proposal [9], which has been successfully used in other applications [10], has been designed and adapted to be used in sport video applications. Xiao Wu et al. [11] also propose an interesting content-based Web video recommender.

Another important challenge of this research is the modeling of audiovisual consumption to infer the user's taste. This modeling has to be adapted to both Web and TV scenarios to allow its introduction in hybrid Web-TV systems. The most recent research in the field of audiovisual recommendation systems with implicit information has been developed by Hyoseop et al. [12] and Zhiwen et al. [13]. They propose systems that directly relate the consumption to the interest in a linear way, according to expression (1):

$$
R_{d}=\frac{\sum_{i=1}^{m} c_{i}}{T_{d}}+T_{d} \cdot \sum_{j=1}^{n} s_{j}+\sum_{k=1}^{p} a_{k}
$$

$\mathbf{R}_{\mathbf{d}}$ is the rating inferred from the behavior of the user. The first term of the sum accounts for the audiovisual consumption: $\mathbf{c}_{\mathbf{i}}$ is the user consumption period of an item, and $\mathbf{T}_{\mathbf{d}}$ is the total duration of the item. The other two terms of the sum, related to storage and bookmarks, are considered for recorded contents, not relevant in our scenario. Therefore, the final rating is only a proportional interpolation of the consumption time.

In this paper, the consumption modeling definition is an evolution of these approaches, including specific aspects described in Section $\mathrm{V}$, with the addition of new modeling stages based on statistical and artificial intelligence processes (Section VI). Other studies about implicit information modeling which have influenced our approach are those of Syeda-Mahmood and Ponceleon [14]. They start recording some events, shot by certain users, to allow the user to preview videos in a search context. Then, they model some observable parameters as play, pause, stop, fast-forward, rewind, etc., by means of an HMM, which yields a particular description about the situation of the user with respect to an item: "Curious", "Aimless browse", "Found something interesting", "Abandoned interest", "Looking for something", "Resumed interest", "Found what I wanted", "Undetermined", "None of the above", "Did not find what I wanted".

Finally, Zimmerman et al. [15] propose a scenario closer to real-time recommendation. They use a rigid model to decide whether a user will consume a piece of content, according to his/her past behavior. They make a binary decision relying on the Bayesian classifier defined by Pazzani in 1998 [16] (and first proposed by Duda and Hart [17]), and decision trees based on Quinlan studies [18]. To design the system, some rules are defined based on content metadata and user profile information.

In conclusion, these studies can be summarized into three different methods, which could be applicable to our scenario. Their characteristics are summarized in Table I and will be compared with our approach in Section VIII.
TABLE I

Possible Approaches to Our Problem

\begin{tabular}{|c|c|}
\hline Approaches & Main characteristics \\
\hline Martinez et al. [5] & $\begin{array}{l}\text { - Hybrid system: content-based and } \\
\text { collaborative filtering. } \\
\text { - Content-based approach based on ontology. } \\
\text { - Items defined only based on one concept. } \\
\text { - Input data from explicit rating of users. } \\
\text { - System implemented on server side. }\end{array}$ \\
\hline Xiao Wu et al. [11] & $\begin{array}{l}\text { - Content-based system. } \\
\text { - Computes only similarity among items. } \\
\text { - Input data from video consumption. } \\
\text { - User profiles not stored: only last video } \\
\text { consumption is taken into account. } \\
\text { - Graphical techniques to obtain similarity. }\end{array}$ \\
\hline Shin et al. [12] & $\begin{array}{l}\text { - Content-based system. } \\
\text { - User behavior profiling. } \\
\text { - Input data from video consumption: in our } \\
\text { scenario, only consumption time would be used. } \\
\text { - Items defined only based on one concept, } \\
\text { using TV-Anytime. }\end{array}$ \\
\hline
\end{tabular}

\section{OUR APPROACH AND ATTRIBUTE DEFINITION}

Our approach is based on the idea that each user wants to consume different things for many different reasons. The proposed recommender system takes into account the multiple factors that can make a user like a particular sports video of the Olympic Games. Four factors have been selected to characterize the taste of the users in this knowledge domain: Sports, Round, Nationality and Athletes. Each of these attributes has a different nature, so they cannot be modeled in a homogeneous way.

1) Sport. It represents the sport competition of the video, such as Men Football, Women Basketball, or Women Badminton. Some users prefer certain sports, so they consume them regularly.

2) Round. It shows the round of the match, or the stage of the competition, such as final, semifinal, preliminaries, etc. Some users are especially interested in the final rounds of the competition.

3) Nationality. It displays the countries involved in the competition of the video. Some users are especially interested in the competitions where their own nationality is represented.

4) Athletes. It represents the athletes involved in competition of the video. It is important because some users are especially interested in following the participation of some relevant competitors.

These attributes are obtained by the system from the metadata information sent in the SportsML XML file, associated to each video. Each of these four attributes influences each user in a different way, and to a different degree. Different attribute values are applied to each user. Using these attributes as values for each video, the system models the audiovisual consumption of the users to obtain two results:

1) Attribute Relevance (AR): This is the percentage of influence that a given attribute has for each user. It is measured in a continuous $0-1$ scale. The sum of the AR value of the four attributes for each user has to be 1 .

2) Attribute Value Certainty ( $A V C$ ): Is measures the possible values of each attribute. These values are different for each 


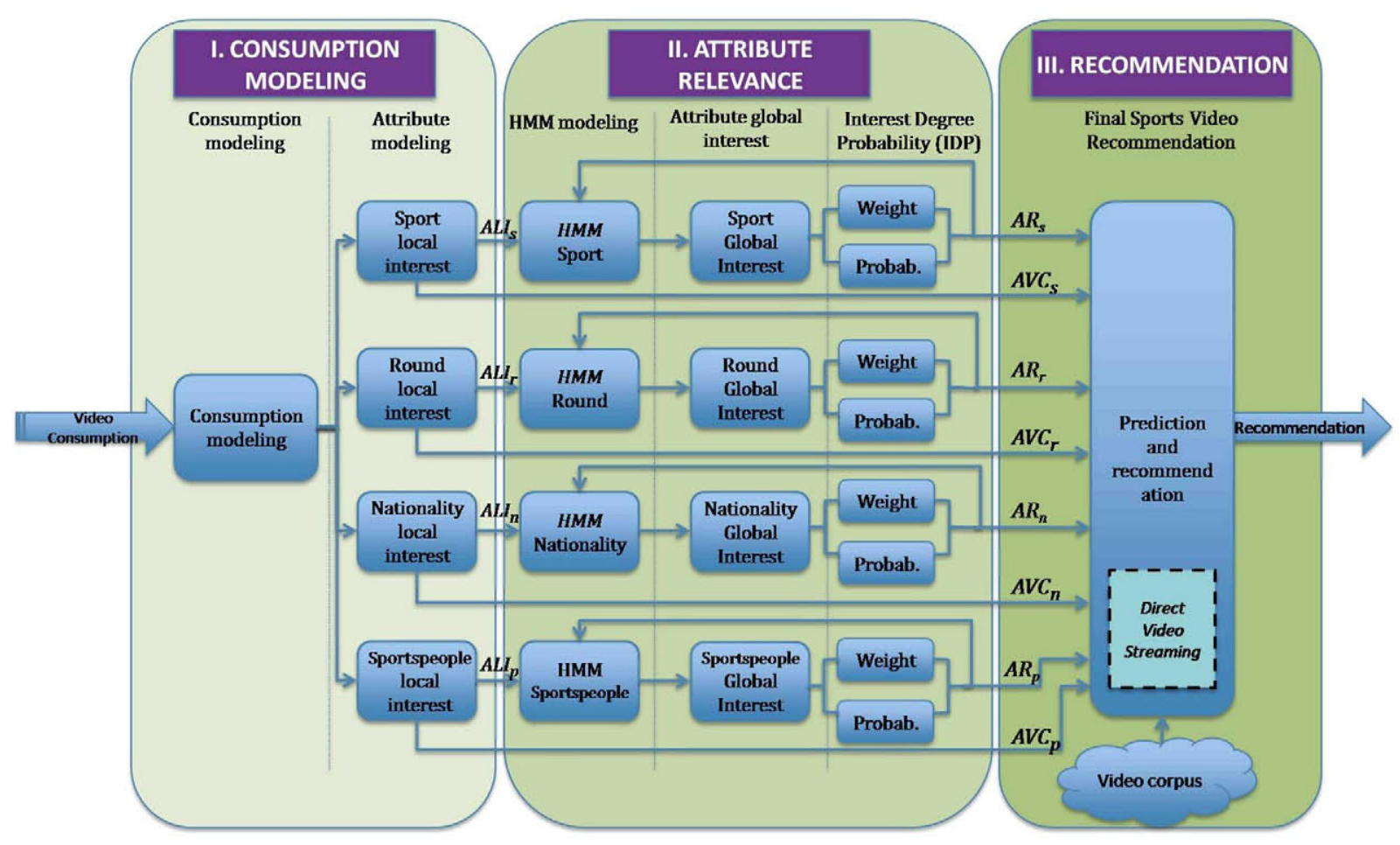

Fig. 1. System architecture.

user, and each has a certain magnitude associated, which lies within a discrete scale from 1 to 5 . For example, for the user $u_{1}$, the attribute Sport may have two possible values, football and basketball; if the first one is the favorite sport of $u_{1}$, it will have a magnitude of 5 ; if the user likes basketball, but less than football, it will have a smaller value, such as 3 or 4 . AVC measurement is applied to three of the four attributes, since for one of them, the Round attribute, it does not make sense. The AVC value for Round is constant for all users, because all users prefer (if this attribute is important for them) final rounds to first ones.

It is important to distinguish both results, AR and AVC. For example, imagine two users who are only influenced by the Sport attribute: one of them only likes football and the other only likes basketball; AR value will be the same for both users, 5 , whereas AVC value will be the following: 5 for football and 1 for basketball for the first user; 5 for basketball and 1 for football, for the second user.

The final predicted rating that the recommender system infers for one video associated to a specific user comes from the combination of both partial results, $A R$ and $A V C$, and will be explained in Section VII.

\section{SYSTEM ARChITECTURE}

Three main stages can be observed in the system architecture. The end-to-end process starts with the acquisition of the user's audiovisual consumption data, and ends with the final recommendation.

Fig. 1 shows the complete process, which is divided into three stages. In the consumption modeling stage, explained in Section V, the data from the user interface is acquired and a measurement of the local interest for the consumed item (a piece of video content) is generated. The measurement is then converted from the consumption domain to the attribute domain. In other words, the information provided by the last user consumption about the influence of each of the attributes is obtained. At this point, the information is split into four branches. The second stage, explained in Section VI, consists of four parallel processes. These processes infer the global importance of each attribute by taking into account both the past information about the user and the last observed consumption events (an event is a single visualization of a video by a user). The last stage, explained in Section VII, uses the updated values of AR and AVC to generate the final recommendations to the user.

The architecture presents a similar structure for the two scenarios considered, live and recorded videos. The live scenario presents an extra module in the final recommendation stage. This module performs a filtering of the corpora of videos, and selects those videos which correspond to ongoing or shortly upcoming competitions. This module also extracts data from the XML files which are generated during the video streaming and feeds them to the system.

\section{CONSUMption Modeling AND RELATIONShiP WITH ATTRIBUTES}

\section{A. Consumption Modeling: TV-Scenario}

The calculation of local interest measurement is based on an evolution of Hyoseop's studies [12]. The input data come from the acquisition module. These input data are taken at the points in time when the user starts $\left(u_{n}\right)$ and stops watching $\left(v_{n}\right)$ a piece of content, for the considered $N$ visualization periods. The value $v_{i}-u_{i}$ is the time interval of the visualization at period $i$ (in $\%$ ). This value is weighted by the value of the last moment of 


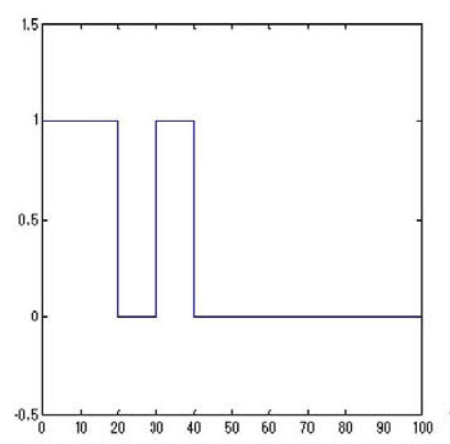

(a)

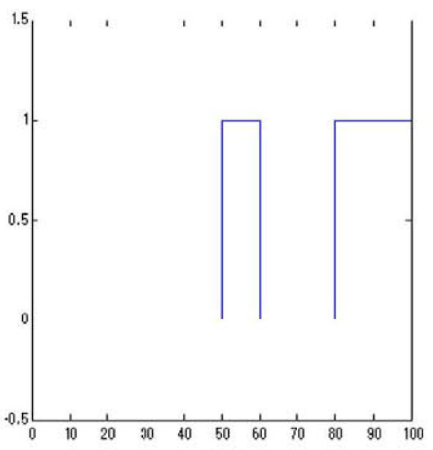

(b)
Fig. 2. Examples of user consumptions over a TV program.

TABLE II

Test Examples of Local InTEREst CALCUlation

\begin{tabular}{ccc}
\hline Consumption time & Starting interest & Final interest \\
\hline $30 \%$ & $\mathrm{I}_{\mathrm{LOC}}=0,08$ & $\mathrm{I}_{\mathrm{LOC}}=0,26$ \\
$60 \%$ & $\mathrm{I}_{\mathrm{LOC}}=0,32$ & $\mathrm{I}_{\mathrm{LOC}}=0,47$ \\
\hline
\end{tabular}

visualization, indicating the last moment with interest for the user. The local interest is expressed in (2):

$$
I_{L O C}=\sum_{n=1}^{N}\left(v_{n}-u_{n}\right) \cdot v_{n} .
$$

Fig. 2 shows two examples of user consumption. It presents the evolution for the consumption of a TV program watched by two different users. The duration of the program is normalized from 0 to 1 , and the visualization periods are identified with a value of " 1 ". The user (a) starts the consumption from the beginning, but his/her interest falls and the consumption stops after doubting for a short period. The user (b) starts the consumption later, but this remains until the end of the TV program.

A linear interpolation of interest from consumption time would give a value of 0.3 out of 1 for both users, since their total consumption time is 0.3 (out of 1). This classic interpolation does not take into account the way in which the user consumes the content. The application of (2) yields different results for each of the users ((3)):

$$
\begin{aligned}
& \mathbf{I}_{\text {LOCa }}=(0.2-0) \cdot 0.2+(0.4-0.3) \cdot 0.4=0.08 \\
& \mathbf{I}_{\text {LOCb }}=(0.6-0.5) \cdot 0.6+(1-0.8) \cdot 1=0.26 .
\end{aligned}
$$

These results show how linear interpolation is penalized because it associates high consumption time to high interest. Using (2), penalization is much bigger for consumptions where visualization occurs mostly at the starting intervals and then fades, since this denotes a lower interest $(0.26$ against 0.08 local interest).

After running several tests (four of them showed in Table II), it has been proved that the inference is not linear, because the system assigns higher weights to the last visualization interval, and takes into account the interval width (penalization is bigger for multiple narrow consumption intervals).

This final value is quantified to be fed into the global interest module as a discrete input ( 5 levels in our implementation, corresponding to 5 different degrees of interest).

\section{B. Consumption Modeling: Internet Scenario}

The Internet scenario has two cases for different types of videos: live (streaming) and prerecorded videos.

The case of live videos is analogous to the TV scenario. Therefore, the expression (2) can also be used for the calculation of the local interest of each piece of content.

The prerecorded videos have different characteristics, therefore another modeling is needed. In this scenario, there are no simultaneous live videos, so the watching period (for instance, starting or final) is not meaningful in the final interest calculation. Apart from that, the consumption of prerecorded videos is not limited to the videos that are on at a particular moment. All videos previously streamed or broadcast are available for users. Because of that, any consumption from the user has to be positively considered. Therefore, one possibility is to apply a binary rating assigning a 1 to consumed items and a 0 to non-consumed items. But this possibility does not take advantage of some data that can be retrieved from the video player: a better adjustment is possible. A binary approach between a consumed or not consumed event is very coarse, because it ignores partial tastes and does not allow a quantization of the degree of interest in the event. This degree of interest can be obtained using the data retrieved from the video player, calculating the consumption time and the amount of skimming and scanning actions from the user.

Besides, the local interest of the user can also be estimated from the consumption time and the skimming and scanning actions of the user. High skimming and scanning means that the user is looking for a segment of the video, and the inferred interest cannot be as high as the interest of a user who watches the complete video.

Thus, taking into account the specificities of this new scenario, a new expression has been defined. Expression (4), which yields a local interest between 0 and 1 , assigns a minimum rating of $a$ for consumed items. The other half of the rating depends on the total consumption time and the amount of skimming and scanning. The latter is represented by parameter $\boldsymbol{s}$, which measures the number of clicks (fast-forwards, rewinds or skips to another part of the video). The meaning of $N, v_{n}$ and $u_{n}$ is analogous to the TV scenario:

$$
\mathbf{I}_{\mathrm{LOC}}=\mathrm{a}+(1-\mathrm{a}) \sum_{\mathbf{n}=1}^{\mathrm{N}} \frac{\left(\mathrm{v}_{\mathbf{n}}-\mathrm{u}_{\mathbf{n}}\right)}{\log _{10}(\mathrm{~s})+1} .
$$

The dependence of the skimming and scanning for the estimation of local interest is shown in Fig. 3 for a value of $a=0.5$. No skimming and scanning is considered for one click, which corresponds to the initial play click.

\section{Attribute Modeling}

The interest of a user in a video has to be adapted to the attributes considered in the recommendation process.

1) Sport: The way to know how relevant the sport of the video is for the user is to only take into account the sports that we know the user likes with a high probability. If the sport has a high AVC value for the user (in the user profile), it is modeled by using (5). If the AR of Sport is high for the user, the AVC value is updated, increasing or decreasing its value:

$$
\mathrm{I}_{\mathrm{LS}}=(-1)^{\mathrm{a}} \cdot \mathrm{I}_{\mathrm{L}} \rightarrow \mathrm{a}=\left\{\begin{array}{l}
1 \rightarrow \text { not in user profile } \\
2 \rightarrow \text { in user profile }
\end{array}\right\} .
$$




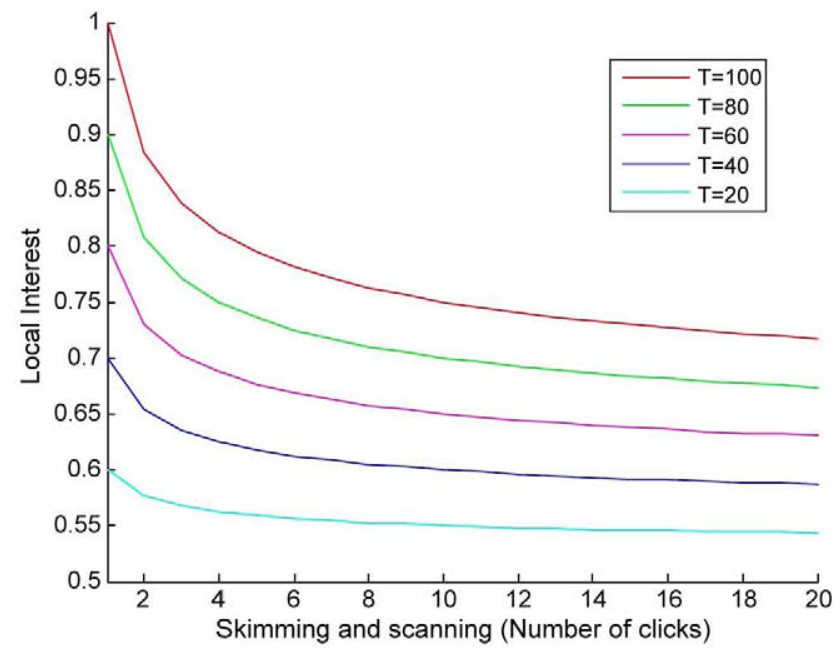

Fig. 3. Dependence of local interest on skimming and scanning.

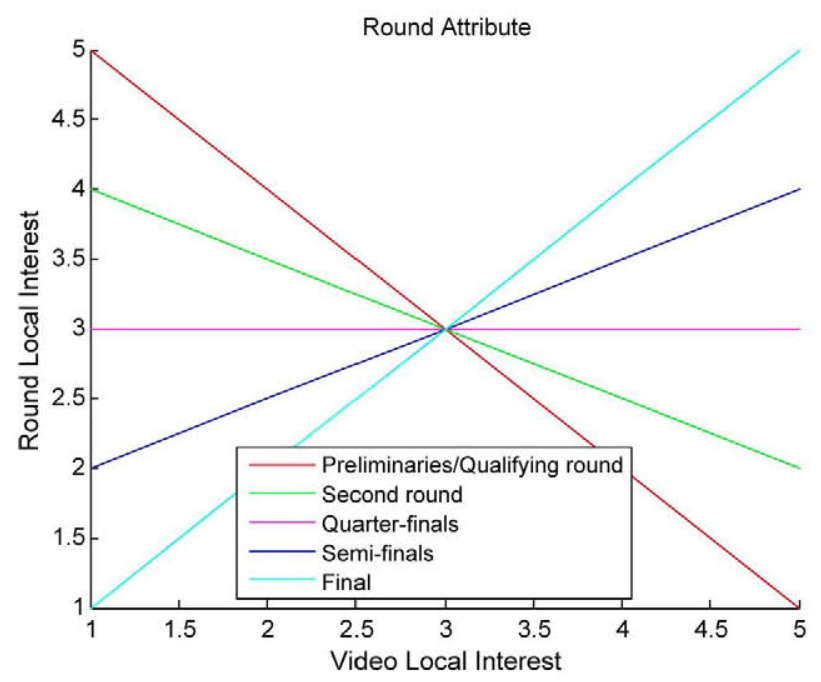

Fig. 4. Round attribute modeling.

2) Round: The modeling of interest for the Round attribute requires the definition of different possible round values (R). Five possible discrete values for $\mathrm{R}$ have been defined (Preliminaries or qualifying round: $R=1$; Second round: $R=2$; Quarter-finals: $\mathrm{R}=3$; Semi-finals: $\mathrm{R}=4$; Final: $\mathrm{R}=5$ ).

If the attribute Round is relevant for a user, it means that he/she will prefer to watch sport videos of the final rounds (with high $\mathrm{R}$ values). If it is not relevant, the value of the round will not determine the consumption of the user, and he/she will consume videos with either high or low round values.

The interest is modeled by expression (6), and it is represented in Fig. 4. First and last rounds are more representative to estimate the interest of the attribute because the reliability of the prediction is increased (they give more information about the attribute: there is more information about the importance of the Round attribute for the user in the consumption of preliminaries or finals than in the consumption of a middle round). Therefore, they have higher slope values in the graph:

$$
\mathrm{I}_{\mathrm{LR}}=\frac{(\mathrm{R}-3)}{2} \cdot \mathrm{I}_{\mathrm{L}}+\frac{(5-\mathrm{R})}{2} \cdot 3 .
$$

3) Nationality: The modeling of Nationality attribute is analogous to the Sport attribute, but it is always taken into account because only the own nationality is used to obtain the final value. Only two cases are possible: a video with the presence of competitors with the same nationality of the user or videos with competitors from other countries:

$$
\mathrm{I}_{\mathrm{LN}}=(-1)^{\mathrm{a}} \cdot \mathrm{I}_{\mathrm{L}} \rightarrow \mathrm{a}=\left\{\begin{array}{l}
1 \rightarrow \text { not own nationality } \\
2 \rightarrow \text { own nationality }
\end{array}\right\} .
$$

4) Athletes: This attribute's modeling is analogous to Sport attribute, following expression (8):

$$
\mathrm{I}_{\mathrm{LA}}=(-1)^{\mathrm{a}} \cdot \mathrm{I}_{\mathrm{L}} \rightarrow \mathrm{a}=\left\{\begin{array}{l}
1 \rightarrow \text { not in user profile } \\
2 \rightarrow \text { in user profile }
\end{array}\right\} .
$$

In this module, there are two output parameters for each attribute: the attribute value certainty (AVC) and the attribute local interest (ALI). Both parameters are quantified using a linear quantization to obtain a discrete output. The ALI parameter is used to obtain the relevance of each attribute for the users. This stage is explained in Section VI. The AVC parameter indicates the preferred value of the user for each attribute, and its numeric quantization. For example, Football and Basketball can be stored as preferred sport values, and the AVC of each one is obtained as the summation of the number of consumptions. This number of consumptions is normalized between the limits selected in the design (from 1 to 5 in our implementation) to obtain the final $\mathrm{AVC}$ values.

\section{INFERENCE OF THE ATtRibute RELEVANCE (AR)}

The global interest is considered by modeling the quantified values of local interest (ALI) of a user for an item, and then the general Attribute Relevance (AR) for this user is obtained. The module is composed of two main stages: an adapted HMM stage (in Fig. 1, HMM modeling and attribute global interest) and a Bayesian inference final stage (in Fig. 1, interest degree probability). Markov models have been selected due to their high performance in temporal states modeling, since the events relevant in this paper are local items that happen over time. In this case, two kinds of states are considered: observable events, which represent local items consumption, and interest states, which are the outputs of the system, and represent the relevance of each attribute for a specific user. Interest states are directly related to both the previous interest state and the current consumption events. A model which establishes a relationship between certain parameters and measurable events is necessary. HMMs are very useful for this type of modeling, since they allow interest states to be the non-visible states on an HMM (hidden states), while consumption events are the measurable related-to-state events.

In addition, the implementation of this model has low computational cost and does not require a big storage module, which is very important when a client-based architecture is implemented.

The relationship of the global interest measurement module with a classic HMM is shown in Fig. 5. The final global interest is the value of the last hidden state inferred.

As in a classic HMM, there is an initial probability, a transition probability and an emission probability. The initial probability is used when there is no explicit additional data, as a 


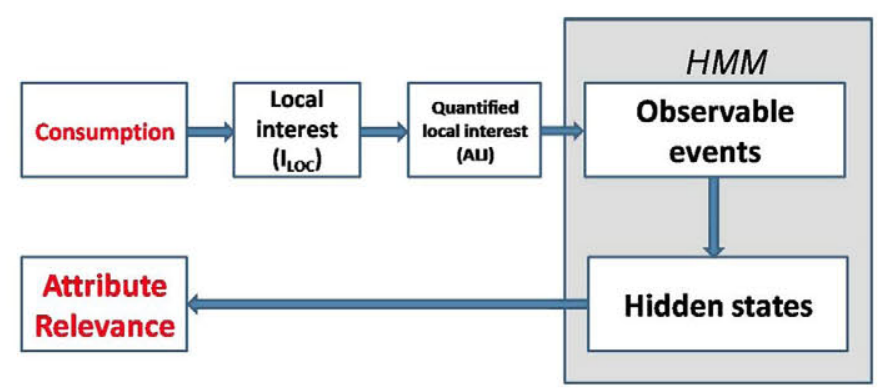

Fig. 5. Relationship with a hidden Markov model.

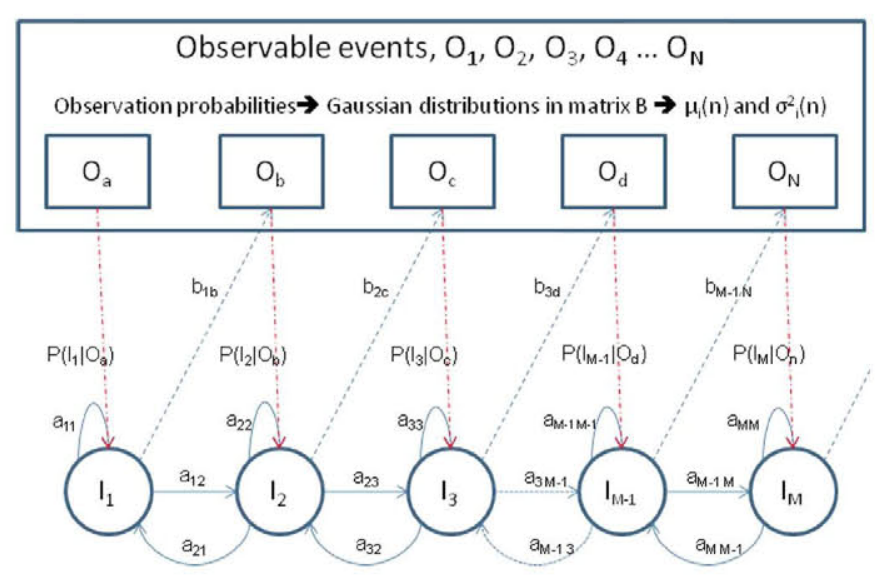

$M$ interest states $\rightarrow$ transition probabilities in matrix $A$

Fig. 6. Modifications to the classic HMM.

Normalized Gaussian; the transition probability is re-calculated (at each new local consumption time) as Gaussian distributions according to the observed changing tendency and is represented in the first matrix, which we denote as A; the emission probability, associated to the second matrix (matrix B) is modeled by Gaussian distributions too, which consider the variations in the consuming sequences observed for the same attribute.

The proposed HMM is shown in Fig. 6 which, for legibility purposes, shows a simplified model: the real system is an ergodic HMM, whose states and observable events that can be reached from any other state. The figure also depicts a change from a classic HMM, since it introduces a relationship from the observable events to the hidden states (represented with red dotted arrows). This relationship represents the instant interest inferred for an attribute just after the consumption of each local item. The way to carry out the selection is to compare the probabilities of each possible interest state associated to the last consumption and choose the highest one.

The Bayesian inference stage is used to obtain the probabilities. In the hidden Markov process, the number of states of the model is defined depending on the desired granularity in the obtained interest. For example, a five-state model will provide a range of Attribute Relevance between 1 and 5. To simplify the implementation, the number of observable events chosen (according to the number of quantification levels) is equal to the number of states of the HMM.
TABLE III

Matrix Distribution Characterization

\begin{tabular}{|c|c|c|}
\hline & $\begin{array}{c}\text { User } \\
\text { effusiveness }\end{array}$ & $\begin{array}{c}\text { User resistance to } \\
\text { change }\end{array}$ \\
\hline General & Mean-Matrix A & Variance-Matrix A \\
\hline Each Attribute & Mean-Matrix B & Variance-Matrix B \\
\hline
\end{tabular}

The HMM is trained dynamically to improve the precision throughout the user consumption time, and to register the possible changes of the user tendency.

The dynamic changes of the model are related to the probability distributions in matrices $\mathrm{A}$ (transition probability) and $\mathrm{B}$ (emission probability). Matrix A refers to the general behavior of the user: it considers the whole consumption of the user and reveals the tendency or resistance to the change inherent to each user when it comes to the audiovisual consumption habits (general for any attribute). On the other hand, matrix B reveals the direct influence of each attribute on the user. These characteristics are summarized in Table III.

Matrix A has a Gaussian distribution probability for each row (the probability of changing from one state/degree of interest to another), and is modeled according to the tendency of a user to change her/her degree of interest with respect to any global item. Therefore, all these changes of the degree of interest are considered so as to recalculate the mean and the variance associated with every state. The variance values are updated after every new consumption based on calculated results (tendency of influence). The mean values are computed for every state, according to the expression (9), where $c(i)$ is a factor that depends on the convergence of the variance, and is also used to filter outliers. For example, a big uncertainly in the last consumption will yield a $c(i)$ value very close to zero, and the new mean will be very similar to the previous one:

$$
\mu_{\mathrm{m}, \mathrm{n}}=\mu_{\mathrm{m}, \mathrm{n}-1}+\mathrm{c}(\mathrm{i}) \cdot \frac{\left(\mathrm{I}_{\mathrm{n}}-\mu_{\mathrm{m}, \mathrm{n}-1}\right)}{\mathrm{n}}
$$

where $\mu, \mathrm{m}, \mathrm{n}$ is the value of the mean value at the $m$ state after consumption $n, \mu_{\mathrm{m}, \mathbf{n}-1}$ is the previous value of that mean, and $\mathrm{I}_{\mathbf{n}}$ is the degree of interest after consumption $\boldsymbol{n}$.

Similarly, the modeling of matrix B is done according to the mean and variance of the Gaussian distribution of each of the matrix rows. The mean is evaluated to model the subjectivity of each user, and is obtained by comparing the correspondence between the consumption sequences and the inferred interest for a global item. The variance is obtained by studying the evolution and regularity of the consumption sequences for each attribute.

The different values of these probabilities are recalculated at every iteration, and the precision value is fed back to the system. This determines the mean and variance of every Gaussian distribution.

The complementary process for the HMM is the Bayesian inference stage. It calculates, using parameters from the HMM, the probability of reaching a given Interest Degree, $I D P$, which depends on the previous interest (previous state) and the last consumption (last detected event). It is computed according to (10), where $I_{n}$ and $O_{n}$ represent the degree of interest (relevance of the attribute) and the consumption at point in time $n$, respectively. By means of several transformations, related to 


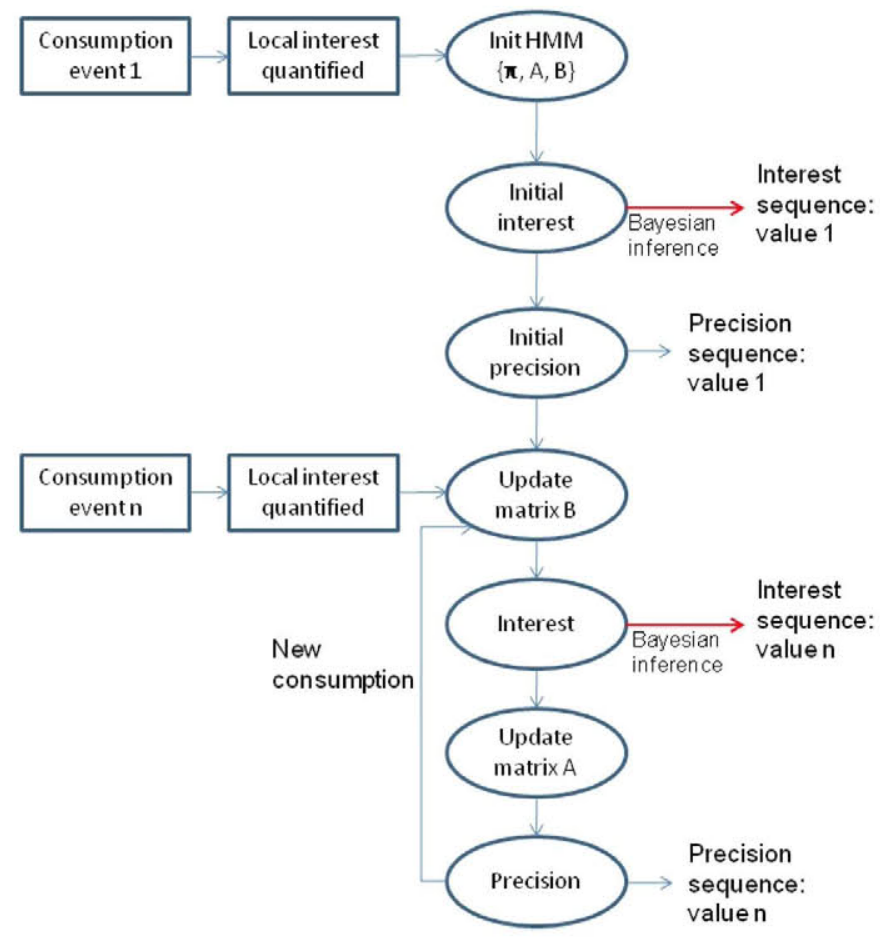

Fig. 7. HMM and Bayesian inference algorithm diagram.

Bayes theorem and other probabilistic properties [19], it is possible to represent the probability in terms of the HMM matrix parameters: $a_{i, j}$ is the (i,j) coefficient of transition probability matrix, $b_{i, j}$ the (i,j) coefficient of emission probability matrix, $\widehat{\mathrm{P}}_{\mathbf{n}}$ the value of precision for the last chosen state, and $\alpha$ is an adjustable parameter that depends on user characteristics (in our tests $\alpha=2$ has been considered for all users, as it gives the best average results, according to the tests explained in Section VIII):

$$
\begin{aligned}
\operatorname{IDP}_{\mathrm{n}} & =\mathrm{P}_{\mathrm{n}}\left(\mathrm{I}_{\mathrm{n}+1}\right)=\mathrm{P}^{\alpha}\left(\mathrm{I}_{\mathrm{n}+1} \mid \mathrm{I}_{\mathrm{n}}\right) \cdot \mathrm{P}\left(\mathrm{I}_{\mathrm{n}+1} \mid \mathrm{O}_{\mathrm{n}+1}\right) \cdot \mathrm{P}\left(\mathrm{I}_{\mathrm{n}}\right) \\
& =\mathrm{a}_{\mathrm{n}, \mathrm{n}+1}^{\alpha} \cdot \mathrm{b}_{\mathrm{n}+1, \mathrm{n}+1}^{\alpha} \cdot \widehat{\mathrm{P}}_{\mathrm{n}} .
\end{aligned}
$$

The HMM and the Bayesian inference stage are combined in the designed algorithm, represented in Fig. 7. The values of HMM are updated at each iteration, using the quantified local interest (corresponding to each consumption), as input.

\section{RECOMMENDATION STAGE}

The access to the final stage of the recommender system is independent of the other stages, but the data about user preferences generated in the other stages is required.

For a given user, this recommendation stage generates a rating for each video. Other systems use different types of weighted recommendation, based on user's preferences or its associated stereotype [20]-[22]. In our approach, the generated rating $\left(\mathrm{W}_{\mathbf{T}}\right)$ is obtained by adding the partial weights of the matching between the attributes of the video and the previously inferred user preferences:

$$
\mathrm{W}_{\mathrm{T}}=\mathrm{W}_{\mathrm{R}}+\mathrm{W}_{\mathrm{N}}+\mathrm{W}_{\mathrm{S}}+\mathrm{W}_{\mathrm{P}} .
$$

The expressions used for the calculation of partial weights are defined in (13) for Round, (14) for Nationality, and (15) for
Sport. Athletes attribute is defined below. The expressions have been obtained by a parameterization of the input data. These are generalized expressions, whose final values depend on the scale of $\mathrm{AR}$ and weights chosen by the designer of the system. $\mathrm{L}_{\mathrm{ha}}$ and $L_{\mathrm{la}}$ values correspond to the upper and lower extremes of the AR scales. $\mathrm{L}_{\mathrm{hw}}$ and $\mathrm{L}_{\mathrm{lw}}$ values are adjusted to set the upper and lower extremes of the output attribute weights. Typically, these limits will be the same for the four attributes, but it is possible to modify them in some specific applications to give special relevance to one or more attributes. $\mathrm{AR}_{\mathrm{a}}$, and $\mathrm{AVC}_{\mathrm{a}}$, which come from the previous module, are the values of the Attribute Relevance and Attribute Value Certainty for the attribute $\boldsymbol{a}$. The user profile $U p$, defined in (12), is a vector of characteristic Sets of user $\mathrm{p}$, containing information about the user's nationality or favorite nationalities $\left(\mathrm{N}_{\mathrm{p}} \subset \mathrm{N}\right.$, where $\mathrm{N}$ is the set of all possible nationalities), favorite sports ( $S_{p} \subset S$, where $S$ is the set of all possible sports), and favorite athletes $(\mathrm{Ap} \subset \mathrm{A}$, where $\mathrm{A}$ is the set of all possible athletes):

$$
\mathrm{U}_{\mathrm{P}}=\left(\mathrm{N}_{\mathrm{p}}, \mathrm{S}_{\mathrm{p}}, \mathrm{A}_{\mathrm{p}}\right)
$$

\section{Round:}

$\mathrm{W}_{\mathrm{R}}=\mathrm{L}_{\mathrm{lw}}+\left(\mathrm{L}_{\mathrm{hw}}+\mathrm{L}_{\mathrm{lw}}\right) \cdot\left(\frac{\mathrm{R}-1}{\mathrm{n}-1}\right) \cdot\left(1+\frac{\mathrm{AR}_{\mathrm{R}}-1}{\mathrm{~L}_{\mathrm{ha}}-\mathrm{L}_{\mathrm{la}}}\right)$

$\rightarrow \forall \mathrm{R} \in \mathrm{Z}[1, \mathrm{n}]$

where $\mathrm{R}$ is the value of the round for the given sport event and $\mathrm{n}$ is the total number of rounds considered in the design of the system.

Nationality:

$$
\begin{aligned}
\mathrm{W}_{\mathrm{N}}= & \left(\frac{\mathrm{L}_{\mathrm{hw}}-\mathrm{L}_{\mathrm{lw}}}{\mathrm{L}_{\mathrm{ha}}-\mathrm{L}_{\mathrm{la}}}\right) \cdot \mathrm{AR}_{\mathrm{N}} \rightarrow \exists \mathrm{n}_{\mathrm{i}} \in \mathrm{N} \mid\left\{\mathrm{n}_{\mathrm{i}}\right\} \subset \mathrm{Np} \\
\mathrm{W}_{\mathrm{N}}^{\prime}= & \mathrm{L}_{\mathrm{lw}}+\frac{1}{(\mathrm{P}-1)} \cdot\left(\frac{\mathrm{L}_{\mathrm{iw}}-\mathrm{L}_{\mathrm{hw}}}{\mathrm{L}_{\mathrm{ha}}-\mathrm{L}_{\mathrm{la}}}\right) \cdot\left(\mathrm{AR}_{\mathrm{N}}-\mathrm{L}_{\mathrm{la}}\right) \\
& \rightarrow \forall \mathrm{N} \not \subset \mathrm{Up}
\end{aligned}
$$

where $\mathrm{N}$ is the Set of the nationalities of the competitors of the sport event, $\mathrm{Np}$ is the Set of preferred nationality values (usually, only the user's own nationality) of the user and $\mathrm{P}$ is the penalization $(\mathrm{P} \in \mathrm{Z}(1, \mathrm{~m}])$ if there is no competitor from the user's country.

Sport:

$$
\begin{aligned}
\mathrm{W}_{\mathrm{S}}= & \mathrm{L}_{\mathrm{lw}}+\left(\mathrm{L}_{\mathrm{hw}}-\mathrm{L}_{\mathrm{lw}}\right) \cdot\left(\frac{\mathrm{AVC}_{\mathrm{S}}-1}{\mathrm{~m}-1}\right) \cdot\left(\frac{1+\mathrm{AR}_{\mathrm{S}}-1}{\mathrm{~L}_{\mathrm{ha}}-\mathrm{L}_{\mathrm{la}}}\right) \\
& \rightarrow \forall \mathrm{AVC}_{\mathrm{S}} \in \mathrm{Z}[1, \mathrm{~m}] \\
\mathrm{W}_{\mathrm{S}}^{\prime}= & 1+\frac{1}{\mathrm{P}} \cdot\left(\frac{\mathrm{L}_{\mathrm{hw}}-\mathrm{L}_{\mathrm{lw}}}{\mathrm{L}_{\mathrm{ha}}-\mathrm{L}_{\mathrm{la}}}\right) \cdot\left(\mathrm{AR}_{\mathrm{S}}-1\right) \rightarrow \forall \mathrm{S} \not \subset \mathrm{Up}
\end{aligned}
$$

where $\mathrm{m}$ is the number of possible values of $\mathrm{AVC}_{\mathrm{s}}, \mathrm{Up}$ the user profile, $\mathrm{S}$ the sport of the event, and $\mathrm{P}$ the penalization $(\mathrm{P} \in$ $\mathrm{Z}(1, \mathrm{~m}])$ if the sport does not exist in the user profile.

Athletes: The Athletes attribute weight is analogous to Sport weight, but the value of $\mathrm{P}$ is $\mathrm{P}=1$.

In the first approximation, $A V C$ values have been used only for Sport and Athletes attributes, since they are generic for all users and they are implicit in the weight expressions for Round and Nationality attributes. 
Finally, the recommendation process sorts the video rating list and recommends the $\mathrm{N}$ videos with higher inferred rating to the user.

\section{TESTS AND RESULTS}

The system has been implemented in a hybrid platform of Web-TV. It can be accessible from the Internet or from a TV set, supporting the standard HBBTV [23].

For clarity purposes, only three of the four attributes (Round, Sport and Nationality) have been taken into account in the test. The behavior of Athletes attribute is analogous to Sport attribute and it requires a high number of consumptions or explicit information from the user.

The scale limits are chosen from 1 to 5 , for both AR parameters and weights, and penalization has been set to $\mathrm{P}=4$. Therefore, weight expression's values for Round, Nationality and Sport are shown in (16), (17) and (18):

$$
\begin{aligned}
& \mathrm{W}_{\mathrm{R}}=1+\left(1+\frac{\mathrm{AR}_{\mathrm{R}}-1}{4}\right) \cdot(\mathrm{R}-1) \rightarrow \forall \mathrm{R} \in[1,5] \\
& \left\{\begin{array}{l}
\mathrm{W}_{\mathrm{N}}=\mathrm{AR}_{\mathrm{N}} \rightarrow \text { own nationality } \\
\mathrm{W}_{\mathrm{N}}=1-\frac{1}{3} \cdot\left(\mathrm{AR}_{\mathrm{N}}-1\right) \rightarrow \text { other nationalities }
\end{array}\right\} \\
& \left\{\begin{array}{l}
\mathrm{W}_{\mathrm{s}}=\mathrm{AVC}_{\mathrm{S}}+\left(\frac{\mathrm{AR}_{\mathrm{S}}-1}{4}\right) \cdot\left(\mathrm{AVC}_{\mathrm{S}}-1\right) \rightarrow \text { in user profile } \\
\mathrm{W}_{\mathrm{s}}=5-4 \cdot \mathrm{AR}_{\mathrm{S}} \rightarrow \text { not in user profile } \\
\rightarrow \forall \mathrm{AVC} \in[1,5] .
\end{array}\right.
\end{aligned}
$$

Two different sets of videos have been built to run the experiments. Corpus 1 consists of 12 sport videos with different characteristics and its corresponding metadata, and it is used in the training stage to simulate the user consumption. In a real scenario, it will correspond to past events, which the user has had the chance to consume. Corpus 2 (upcoming sport events) consists of 30 videos (Table IV) with their corresponding metadata, and it is used to generate the recommendations.

The implemented systems usually work over a single corpus for both training and recommendation, but the system and testing done with two sets allows for a higher control, more legibility, and a comparison of the results for the different users. A precondition is that videos already consumed by a user are not recommended to this user. Therefore, working with a single corpus makes comparison among different users impossible: after the consumption stage, the pool of videos that can be recommended to each user is different.

The last step to prepare the tests is to define the user profiles. Four different user profiles have been created and some characteristics have been associated to them:

User 1 comes from Canada, and especially likes watching sport competitions from his/her country. He/she also prefers the competitions' final rounds.

User 2 comes from Canada, and is especially interested in some sports (football mainly, but also basketball). This user also prefers the competitions' final rounds.

User 3 comes from Switzerland, and especially likes watching sports competitions when they get to the final rounds. He/she also likes watching videos with Swiss competitors.

\begin{tabular}{|c|c|c|c|c|}
\hline Video & Sport & Round & Nation. 1 & Nation. 2 \\
\hline 1 & Football & Preliminaries & SUI & USA \\
\hline 2 & Football & Preliminaries & CAN & NOR \\
\hline 3 & Football & Preliminaries & BLR & FIN \\
\hline 4 & Football & Preliminaries & GER & SWE \\
\hline 5 & Football & Preliminaries & CZE & SVK \\
\hline 6 & Football & Preliminaries & NOR & USA \\
\hline 7 & Table tennis & Preliminaries & LAT & RUS \\
\hline 8 & Basketball & Preliminaries & CAN & SUI \\
\hline 9 & Basketball & Preliminaries & RUS & SVK \\
\hline 10 & Basketball & Preliminaries & BLR & SWE \\
\hline 11 & Basketball & Preliminaries & CZE & LAT \\
\hline 12 & Water polo & Preliminaries & FIN & GER \\
\hline 13 & Water polo & Preliminaries & NOR & SUI \\
\hline 14 & Ice hockey & Preliminaries & LAT & SVK \\
\hline 15 & Ice hockey & Preliminaries & BLR & GER \\
\hline 16 & Ice hockey & Preliminaries & CZE & RUS \\
\hline 17 & Ice hockey & Preliminaries & CAN & USA \\
\hline 18 & Syncr. swimm. & Preliminaries & FIN & SWE \\
\hline 19 & Badminton & Preliminaries & BLR & SUI \\
\hline 20 & Beach volley & Preliminaries & CAN & GER \\
\hline 21 & Tennis & Preliminaries & CZE & LAT \\
\hline 22 & Tennis & Preliminaries & NOR & SVK \\
\hline 23 & Judo & Quarter-final & SUI & USA \\
\hline 24 & Football & Quarter-final & CAN & RUS \\
\hline 25 & Table tennis & Quarter-final & CZE & FIN \\
\hline 26 & Handball & Quarter-final & SVK & SWE \\
\hline 27 & Archery & Semi-final & FIN & USA \\
\hline 28 & Badminton & Semi-final & CAN & SVK \\
\hline 29 & Handball & Bronze final & FIN & SVK \\
\hline 30 & Football & Final & CAN & USA \\
\hline
\end{tabular}

User 4 is Spanish and a basketball fan.
TABLE IV

RECOMMENDATION CORPUS

TABLE V

USER CONSUMPTION SIMULATION

\begin{tabular}{|l|l|l|l|l|}
\hline User & $\mathbf{1}$ & $\mathbf{2}$ & $\mathbf{3}$ & $\mathbf{4}$ \\
\hline Nat. & CAN & CAN & SUI & ESP \\
\hline Cons: & $\bullet$ Football & $\bullet$ Football & $\bullet$ Basketball & $\bullet$ Basketball \\
\hline Sport & CAN vs. BRA & CAN vs. BRA & LAT vs. CAN & LAT vs. CAN \\
Nat & Quarter final & Quarter final & Final & Final \\
$\mathbf{I}_{\text {Loc }}$ & $80 \%$ & $100 \%$ & $100 \%$ & $100 \%$ \\
& $\bullet \quad$ Tennis & $\bullet$ Basketball & $\bullet$ Badminton & $\bullet$ Basketball \\
& USA vs. CAN & LAT vs. CAN & SUI vs. SWE & LAT vs. USA \\
& Semi-final & Final & Final & Preliminaries \\
& $60 \%$ & $100 \%$ & $100 \%$ & $70 \%$ \\
& $\bullet$ Basketball & $\bullet$ Football & $\bullet$ Table tenn & $\bullet$ Basketball \\
& LAT vs. CAN & ARG vs. BLR & SUI vs. SWE & ARG vs. CAN \\
& Final & Quarter final & Semi-final & Semi-final \\
& $100 \%$ & $80 \%$ & $100 \%$ & $100 \%$ \\
& $\bullet \quad$ Ice hockey & $\bullet$ Football & $\bullet$ Archery & $\bullet$ Basketball \\
& CAN vs. SUI & SUI vs. BRA & USA vs. SWE & CZE vs. FIN \\
& Semi-final & Quarter final & Final & Preliminaries \\
& $90 \%$ & $70 \%$ & $70 \%$ & $90 \%$ \\
\hline
\end{tabular}

According to these profile characteristics, four video consumptions have been associated to each user, using the twelve videos from corpus 1 . These consumptions have been simulated in the real system, and its characteristics are summarized in Table V.

These consumptions are performed in the real system for each of the users, using Corpus 1 . The system infers the relevance that each attribute has for each user, and we can see that the 
TABLE VI

Attribute Relevance (AR) Values InfERred By the System

\begin{tabular}{|c|c|c|c|c|}
\hline \multirow{2}{*}{ Attribute } & \multicolumn{4}{|c|}{ User } \\
\cline { 2 - 5 } & $\mathbf{1}$ & $\mathbf{2}$ & $\mathbf{3}$ & $\mathbf{4}$ \\
\hline Round & 3 & 3 & 5 & 2 \\
\hline Sport & 1 & 5 & 1 & 5 \\
\hline Nationality & 5 & 3 & 4 & 2 \\
\hline
\end{tabular}

TABLE VII

ReCOMmEndation Results. OUR APPROACH

\begin{tabular}{|c|l|l|l|l|}
\hline \multicolumn{5}{|c|}{ Users recommendations } \\
\hline User & 1 & 2 & 3 & 4 \\
\hline Pref 1 & Video 30 & Video 30 & Video 30 & Video 8 \\
\hline Pref 2 & Video 28 & Video 24 & Video 23 & Video 9 \\
\hline Pref 3 & Video 24 & Video 2 & Video 27 & Video 10 \\
\hline Pref 4 & Video 20 & Video 8 & Video 28 & Video 11 \\
\hline Pref 5 & Video 17 & Video 1 & Video 1 & Video 30 \\
\hline
\end{tabular}

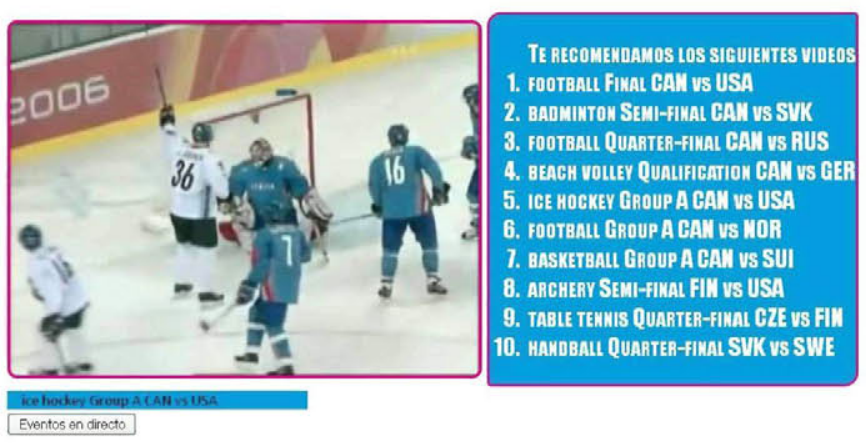

Fig. 8. Recommender system interface: User 1.

results are consistent with the profile definition. These results are shown in Table VI.

bCorpus 1 is replaced by Corpus 2 in the system (past events are replaced by current and upcoming events), and each of the four users obtains different recommendations of the videos from Corpus 2. The first five recommendations for each of the four test users are shown in Table VII.

It can be seen that the generated recommendations are consistent with the defined user profiles.

These results have been directly obtained from the system interface. Fig. 8 shows a screenshot of the interface, which displays the list of recommendations for User 1 (next to the video player), while he/she is consuming an ice hockey video.

In order to compare our results with a simpler system, we have developed a decision tree and tested it in the same scenario, with the same corpus. The decision tree solution is shown in Fig. 9, and the recommendation results are shown in Table VIII.

It can be seen that the recommendation results of the decision tree for users 2 and 4 are the same as the results of our system. However, users 1 and 3 receive different recommendations. The reason for this result is that the decision tree presents a good performance for users with typical behavior. However, less predictable users need a more complex analysis. They need a dynamic and flexible modeling of the attributes, such as the one carried out in our approach.

To obtain a quantitative measurement of the recommender's precision, the correlation between the relevance of an attribute

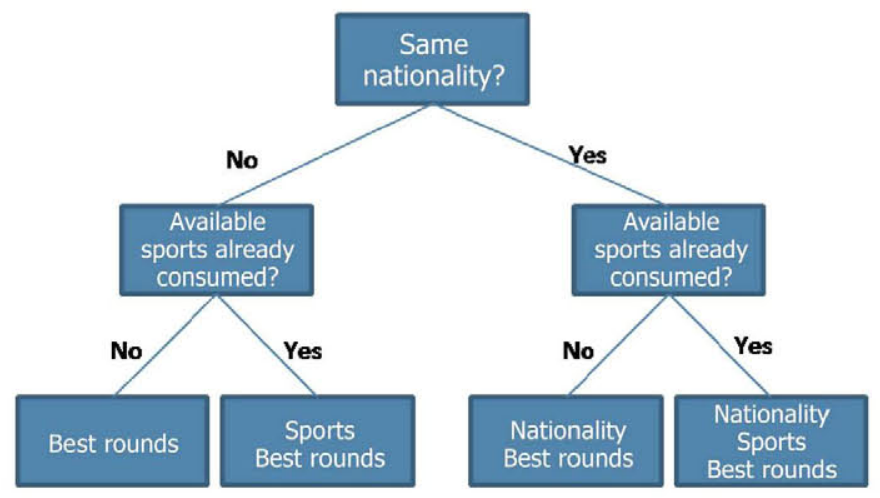

Fig. 9. Decision tree solution.

TABLE VIII

Recommendation Results. Decision Tree Solution

\begin{tabular}{|c|l|l|l|l|}
\hline \multicolumn{5}{|c|}{ Users recommendations } \\
\hline User & \multicolumn{1}{|c|}{1} & \multicolumn{1}{|c|}{2} & 3 & 4 \\
\hline Pref 1 & Video 30 & Video 30 & Video 8 & Video 8 \\
\hline Pref 2 & Video 24 & Video 24 & Video 19 & Video 9 \\
\hline Pref 3 & Video 17 & Video 2 & Video 23 & Video 10 \\
\hline Pref 4 & Video 8 & Video 8 & Video 1 & Video 11 \\
\hline Pref 5 & Video 2 & Video 1 & Video 13 & Video 30 \\
\hline
\end{tabular}

for a user and the relevance of this attribute on the final recommendation list has been obtained.

The relevance of an attribute in the recommendation lists $\left(R_{\mathrm{a}}\right)$ has been obtained taking into account the presence of this attribute and the position of the related items.

For example, the relevance of Round attribute in the recommendation list for User 1 should be similar to his/her AR value $(\mathrm{AR}=3$, as can be seen in Table VI). Expression (19) has been used to compute $R_{\mathrm{r}}$ value, and the result for User 1 is $\mathrm{RR}_{\mathrm{r}}=4.27$ :

$$
\mathrm{RR}_{\mathrm{r}}=\left(\sum_{\mathrm{k}=1}^{\mathrm{NR}} \frac{\mathrm{NR} \cdot \mathrm{pos}_{\mathrm{k}}}{\sum_{\mathrm{i}=1}^{N R} \operatorname{pos}_{\mathrm{i}}} \cdot \frac{\operatorname{pos}_{\mathrm{k}}}{\mathrm{NR}}\right) \cdot \frac{\mathrm{A}}{\operatorname{Max}(\mathrm{RR})}
$$

where NR is the length of the recommendation list $(\mathrm{NR}=5$

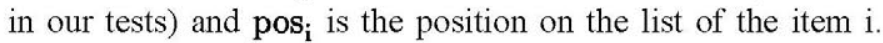
i represents all possible positions in the final recommendation lists (for example, if $\mathrm{NR}=5$, $\mathrm{i}$ goes from 1 to 5 ); while $\mathrm{k}$ represents only the involved items (for example, sports in the user profile or nationality of the user). The term $A / \operatorname{Max}(R R)$ is the normalization value ( $\mathrm{A}=5$ in our test, because we are using a 1 to 5 rating scale) and $\operatorname{Max}(\mathrm{RR})$ is the maximum possible value of the expression for the data of the corpus. In the round example, for example, the maximum 5 value can be reached only if there are enough events of final rounds in the corpus.

Analogously, expressions (20) and (21) estimate the relevance of attributes Sport and Nationality in the recommendation final lists:

$$
\begin{aligned}
\mathrm{RR}_{\mathrm{S}} & =\operatorname{Max}_{\mathrm{S}}\left(\sum_{\mathrm{k}=1}^{\mathrm{N}} \frac{\left(\mathrm{NR}-\mathrm{pos}_{\mathrm{k}}+1\right) \cdot \mathrm{L}_{\mathrm{S}}}{\sum_{\mathrm{i}=1}^{N R} \operatorname{pos}_{\mathbf{i}}}\right) \\
\mathrm{RR}_{\mathrm{N}} & =\left(\sum_{\mathrm{k}=1}^{\mathrm{N}} \frac{\left(\mathrm{NR}-\mathrm{pos}_{\mathbf{k}}+1\right) \cdot \mathrm{L}_{\mathrm{S}}}{\sum_{\mathrm{i}=1}^{N \mathrm{NR}} \operatorname{pos}_{\mathrm{i}}}\right) .
\end{aligned}
$$


TABLE IX

OBTAINED VALUES AND CORRELATIONS

\begin{tabular}{|c|c|c|c|c|}
\hline User & National. & Round & Sport & Correlation( $(\%)$ \\
\hline 1 (AR value) & 5 & 3 & 1 & \multirow{2}{*}{96.42} \\
\hline 1 (Our System) & 5 & 4.27 & 2.67 & \\
\hline 1 (D. Tree) & 5 & 3.47 & 3.33 & 94.37 \\
\hline 2 (AR value) & 3 & 3 & 5 & \multirow{2}{*}{96.88} \\
\hline 2 (Our System) & 4.67 & 3.47 & 4.33 & \\
\hline 2 (D. Tree) & 4.67 & 3.47 & 4.33 & 96.88 \\
\hline 3 (AR value) & 4 & 5 & 1 & \multirow{2}{*}{92.43} \\
\hline 3 (Our System) & 1.67 & 4.68 & 2 & \\
\hline 3 (D. Tree) & 5 & 1.69 & 1.67 & 83.96 \\
\hline 4 (AR value) & 2 & 2 & 5 & \multirow{2}{*}{99.78} \\
\hline 4 (Our System) & - & 1.53 & 4.67 & \\
\hline 4 (D. Tree) & - & 1.53 & 4.67 & 99.78 \\
\hline \multicolumn{4}{|c|}{ Correlation Mean Value (Our System) } & 96.38 \\
\hline \multicolumn{4}{|c|}{ Correlation Mean Value (Decision Tree) } & 93.75 \\
\hline
\end{tabular}

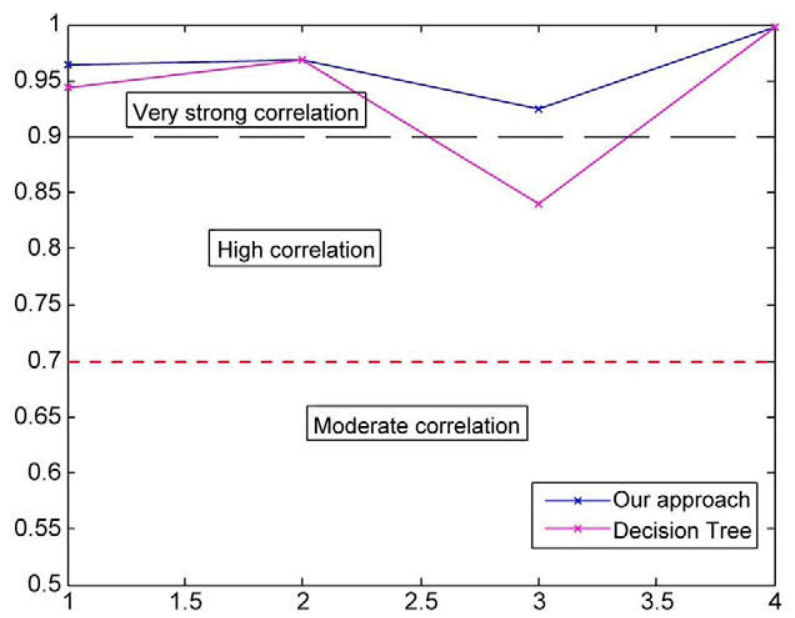

Fig. 10. User correlation values (thresholds from [25]).

Using these data, which can be seen in Table IX, correlation has been computed for each user, comparing the recommendations of our approach and the recommendations of the decision tree. The results are shown in Fig. 10. Correlation has been obtained using the Pearson correlation coefficient [24].

The mean correlation for our approach is higher than 0.95 , which means that there is a very high degree of correlation between expected and obtained values, and a very strong correlation exists for the four considered users. In contrast, as stated above, the decision tree solution works well for typical users, but it gets worse for people with less predictable behavior.

Finally, a qualitative comparison between our approach and other approaches is shown in Table X.

The problems of our approach will appear in an uncontrolled scenario, because our system needs specific attribute modeling. A controlled scenario allows us to take into account involved attributes (i.e., sport, round, nationality and athletes in our sport videos for the Olympic Games scenario), but an uncontrolled scenario can be applied to our system if an ontology [7] is included to generate the attribute modeling dynamically.
TABLE X

COMPARISON WITH OTHER APPROACHES

\begin{tabular}{|c|c|c|}
\hline Other approaches & $\begin{array}{c}\text { Advantages of our } \\
\text { approach }\end{array}$ & $\begin{array}{c}\text { Problems of } \\
\text { application in our } \\
\text { scenario }\end{array}$ \\
\hline Martinez et al. [5] & $\begin{array}{l}\text { - We do not need a } \\
\text { minimum number of } \\
\text { users. } \\
\text { - Our approach is more } \\
\text { flexible, because every } \\
\text { item is described by } \\
\text { several attributes } \\
\text { - Our approach takes } \\
\text { into account the tendency } \\
\text { and personal tastes } \\
\text { evolution, because of the } \\
\text { HMM stage. }\end{array}$ & $\begin{array}{l}\text { - We need a } \\
\text { client-side approach } \\
\text { - We need a way } \\
\text { to infer user } \\
\text { preferences. This } \\
\text { approach asks them } \\
\text { to the user in an } \\
\text { explicit way. }\end{array}$ \\
\hline Xiao Wu et al. [11] & $\begin{array}{l}\text { - We take into account } \\
\text { all video consumptions of } \\
\text { the user, without storing } \\
\text { all the information: we } \\
\text { update the model in real } \\
\text { time. } \\
\text { - We take into account } \\
\text { four different } \\
\text { characteristics of videos, } \\
\text { which is objective } \\
\text { information. They } \\
\text { consider external links, } \\
\text { subjective information. }\end{array}$ & $\begin{array}{l}\text { - We need a } \\
\text { model which takes } \\
\text { into account user } \\
\text { preferences, not } \\
\text { only item similarity. } \\
\text { - We need a } \\
\text { system which stores } \\
\text { user preferences to } \\
\text { be used with } \\
\text { dynamic content. } \\
\text { Because of that, } \\
\text { item-preferences } \\
\text { should be translated } \\
\text { into attribute } \\
\text { preferences. }\end{array}$ \\
\hline Shin et al. [12] & $\begin{array}{l}\text { - Our approach infers } \\
\text { user tastes not only from } \\
\text { consumption time, but } \\
\text { also from the way its } \\
\text { produced. } \\
\text { - Our approach } \\
\text { associates several } \\
\text { attributes to each item: } \\
\text { more flexible and precise. }\end{array}$ & $\begin{array}{l}\text { - We need a } \\
\text { consumption model } \\
\text { which takes into } \\
\text { account TV and } \\
\text { Internet scenarios, } \\
\text { and live and } \\
\text { prerecorded videos. }\end{array}$ \\
\hline
\end{tabular}

\section{CONCLUSIONS AND FUtURE WORK}

This paper has presented a Recommender System for Sport Videos. The validation tests applied show the successful performance results. The paper has proposed a new recommendation method transparent to the user, who only has to consume videos as he/she would do in any video distribution platform. The system takes into account how the preferences of users change over time.

One of the main advantages of this system is that it is integrated on the client-side, and it avoids a lot of congestion and computational problems. Besides, the recommendation system does not need other users so as to work properly. The system will work even with a single user. Another advantage is that the system generates effective and useful recommendations from the first consumption: cold start problems are avoided. However, while video consumption increases, recommendations are more accurate, decreasing the risk of over-specialization [26] since new nuances about user preferences are incorporated.

Several research lines are opened with this work. One of the most important lines for the future is to consider the video style and audiovisual narrative to generate recommendations. Characteristics such as the kind of shots, the point of view of the 
camera, or the movement of images can be modeled [27] and used to recommend more suitable videos for users.

Another interesting working line is the recommendation of fragments of videos: highlights can be extracted from videos [28] to generate more specific recommendations.

\section{REFERENCES}

[1] G. Adomavicius and A. Tuzhilin, "Toward the next generation of recommender systems: A survey of the state-of-the-art and possible extensions," IEEE Trans. Knowl. Data Eng., vol. 17, no. 6, pp. 734-749, Jun. 2005.

[2] SportsML 2.0: IPTC G2-Standard. Compliance Guide, Jul. 3, 2008, Draft 4. [Online]. Available: http://www.sportsml.com.

[3] K. Merkel, "Hybrid broadcast broadband TV, the new way to a comprehensive TV experience," in Proc. 2011 14th ITG Conf. Electronic Media Technology (CEMT), Mar. 23-24, 2011, pp. 1-4.

[4] B. Sarwar, G. Karypis, J. Konstan, and J. Reidl, "Item-based collaborative filtering recommendation algorithms," in Proc. 10th Int. Conf. World Wide Web, 2001, p. 295, ACM.

[5] A. Martinez, J. Arias, A. Vilas, J. Garcia Duque, and M. Lopez Nores, "What's on TV tonight? An efficient and effective personalized recommender system of TV programs," IEEE Trans. Consum. Electron., vol. 55 , no. 1, pp. 286-294, Feb. 2009

[6] M. Naphade, J. R. Smith, J. Tesic, S.-F. Chang, W. Hsu, L. Kennedy, A. Hauptmann, and J. Curtis, "Large-scale concept ontology for multimedia," IEEE Multimedia, vol. 13, no. 3, pp. 86-91, Jul.-Sep. 2006.

[7] R. Sotelo, Y. Blanco-Fernandez, M. Lopez-Nores, A. Gil-Solla, and J. Pazos-Arias, "TV program recommendation for groups based on multidimensional TV-anytime classifications," IEEE Trans. Consum. Electron., vol. 55, no. 1, pp. $248-256$, Feb. 2009

[8] J. L. Sanchez, F. Serradilla, E. Martinez, and J. Bobadilla, "Choice of metrics used in collaborative filtering and their impact on recommender systems," in Proc. 2nd IEEE Int. Conf. Digital Ecosystems and Technologies, 2008 (DEST 2008), Feb. 26-29, 2008, pp. 432-436.

[9] M. J. Pazzani, "A framework for collaborative, content-based and demographic filtering," Artif. Intell. Rev., vol. 13, no. 5, pp. 393-408, 1999.

[10] S. Pizard, ClaNFi, Clasificador de Noticias Financieras, Instituto de Computación. Facultad de Ingeniería. Universidad de la República Oriental del Uruguay, Aug. 2007. [Online]. Available: http://www.fing. edu.uy/inco/grupos/pln/prygrado/InformeCLANFI.pdf.

[11] X. Wu, Y. Zhang, J. Guo, and J. Li, "Web video recommendation and long tail discovering," in Proc. 2008 IEEE Int. Conf. Multimedia and Expo, Jun. 23-26, 2008, pp. 369-372.

[12] H. Shin, M. Lee, and E. Y. Kim, "Personalized digital TV content recommendation with integration of user behavior profiling and multimodal content rating," IEEE Trans. Consum. Electron., vol. 55, no. 3, pp. 1417-1423, Apr. 2009

[13] Z. Yu, X. Zhou, L. Zhou, and K. Du, "A hybrid similarity measure of contents for TV personalization," Multimedia Syst., May 2010.

[14] T. Syeda-Mahmood and D. Ponceleon, "Learning video browsing behavior and its application in the generation of video previews," in Proc. 9th ACM Int. Conf. Multimedia, Ottawa, ON, Canada, 2001.

[15] J. Zimmerman, K. Kurapati, A. L. Buczak, D. Schaffer, S. Gutta, and J. Martino, "TV personalization system," ch. 5, Design of a TV Show Recommender Engine and Interface, 2004.

[16] D. Billsus and M. J. Pazzani, "Learning collaborative information filters," in Proc. 15th Int. Conf. Machine Learning, Madison, WI, 1998, pp. $46-54$.

[17] R. Duda and P. Hart, Pattern Recognition and Scene Analysis. New York: Wiley, 1973.

[18] R. Quinlan, "Learning efficient classification procedures and their application to chess end games," in Machine Learning: An Artificial Approach, R. S. Michalski, J. G. Carbonell, and T. M. Mitchell, Eds. Palo Alto, CA: Morgan Kaufmann, 1983, vol. 1.

[19] S. Ashkezari-T. and M.-R. Akbarzadeh-T., "Fuzzy-Bayesian network approach to genre-based recommender systems," in Proc. 2010 IEEE Int. Conf. Fuzzy Systems (FUZZ), Jul. 18-23, 2010, pp. 1-7.

[20] R. Forsati, M. R. Meybodi, and A. Rahbar, "An efficient algorithm for web recommendation systems," in Proc. IEEE/ACS Int. Conf. Computer Systems and Applications, 2009 (AICCSA 2009), May 10-13, 2009 , pp. 579-586.

[21] M. Sollenborn and P. Funk, "Category-based filtering and user stereotype cases to reduce the latency problem in recommender systems," in Proc. Advances in Case-Based Reasoning, 6th European Conference, ECCBR 2002 Aberdeen, U.K., Sep. 47, 2002, S. Craw and A. D. Preece, Eds., 2002, vol. 2416, Lecture Notes in Computer Science, pp. $395-420$, Springer.
[22] G. Shani, A. Meisles, Y. Gleyzer, L. Rokach, and D. Ben-Shimon, "A stereotypes-based hybrid recommender system for media items," in Proc. Workshop Intelligent Techniques for Web Personalization, Vancouver, BC, Canada, 2007.

[23] ETSI TS 102 796. Hybrid Broadband Broadcast TV V1.1.1, Jun. 2010.

[24] J. L. Rodgers and W. A. Nicewander, "Thirteen ways to look at the correlation coefficient," Amer. Statist., vol. 42, no. 1, pp. 59-66, Feb. 1988.

[25] I. Johnston, I'll Give You a Definite Maybe: An Introductory Handbook on Probability, Statistics, and Excel, May 2000. [Online]. Available: http://www.mala.bc.ca/ johnstoi/maybe/maybe4.htm.

[26] C. Yu, L. Lakshmanan, and S. Amer-Yahia, "Recommendation diversification using explanations," in Proc. IEEE 25th Int. Conf. Data Engineering, 2009 (ICDE '09), Mar. 29-Apr. 2, 2009, pp. 1299-1302.

[27] Y. Ding and G. Fan, "Segmental hidden Markov Models for viewbased sport video analysis," in Proc. Computer Vision and Pattern Recognition, 2007 (CVPR '07), Jun. 17-22, 2007, pp. 1-8.

[28] A. Hanjalic, "Adaptive extraction of highlights from a sport video based on excitement modeling," IEEE Trans. Multimedia, vol. 7, no. 6, pp. 1114-1122, Dec. 2005

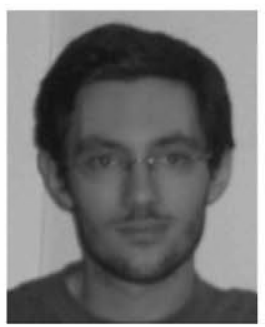

Faustino Sánchez received the Telecom Engineer degree (Hons.) and the Telecom Systems Master degree (Hons.) from the "Universidad Politécnica de Madrid", Madrid, Spain, in 2008 and 2010, respectively, where he is pursuing the $\mathrm{Ph}$.D. degree.

Since 2007 , he has worked as a researcher at the Visual Telecommunications Applications group (GATV) of the "Universidad Politécnica de Madrid". His professional interests include interactivity technologies, audience measure techniques, user behavior modeling, and recommendation systems. Related to this, he has been participating with technical responsibilities in some national projects, and he is author and co-author of several papers and scientific contributions in international conferences and journals.

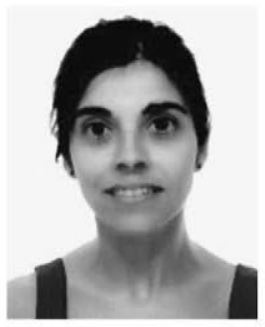

María Alduán received the Computer Engineer degree from Centro Politécnico Superior, Universidad de Zaragoza, Zaragoza, Spain, in 2009. Since 2009 , she has been pursuing the Ph.D. degree and research assistant at the Visual Telecommunications Application Group in the Signals, Systems and Radio Communications Department from E.T.S. Ingenieros de Telecomunicación, Universidad Politecnica de Madrid, Madrid, Spain, where she has been collaborating since 2008 .

She is currently leading the architecture research work in the National project BUSCAMEDIA. She has several publications in international conferences and journals.

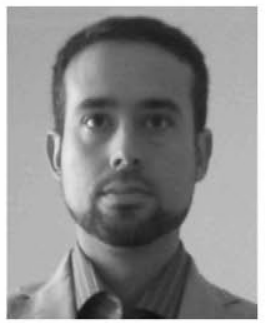

Federico Álvarez (M’07) received the Telecom Engineer degree (Hons.) and Ph.D. degree (cum laude) from the "Universidad Politécnica de Madrid", Madrid, Spain, in 2003 and 2009, respectively.

$\mathrm{He}$ is currently working as an Assistant Professor at the "Universidad Politécnica de Madrid". Since 2003 , he has been working for the research group in the Visual Telecommunications Applications group (GATV) of the "Universidad Politécnica de Madrid". $\mathrm{He}$ has been participating with different managerial and technical responsibilities in several national (for example he is currently the technical coordinator of BUSCAMEDIA) and EU projects. He was the coordinator of EU Framework Programme (FP) projects "ARENA" (IST-024124) and FP7 nextMEDIA (ICT-249065), and currently he is the coordinating INFINITY (ICT-285192). In addition, he had a relevant role in projects such as SEA, AWISSENET, SIMPLE, etc. He is the author and co-author of more than 40 papers and several books (e.g., recently FIA book 2012), book chapters, and patents in the field of ICT networks and audiovisual technologies.

Dr. Álvarez had participated in national and international standardization fora (DVB, CENELEC TC206, etc.). He is a member of the program committee of several scientific conferences. 


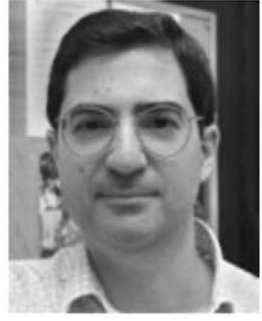

José Manuel Menéndez ( $\mathrm{M}^{\prime} 03$ ) has been a Professor of signal theory and communications since 1996 at the Signals, Systems, and Communications Department of the E.T.S. Ingenieros de Telecomunicación of the Universidad Politécnica de Madrid, Madrid, Spain, and Director of the Visual Telecommunication Application Research Group (G@TV) of the same university since 2004 . He has more than 60 international publications about signal processing and communications, both in international journals and conferences, and many national publications, including a book (in Spanish) for undergraduate engineering level. He has participated or lead more than $80 \mathrm{R}+\mathrm{D}$ projects, including private and public funding (Spanish or European). He also collaborates with Spanish National and Regional entities, the European Commission in the evaluation and review of $\mathrm{R}+\mathrm{D}$ projects, and with several national telecommunication and broadcasting companies as a consultant.

Prof. Menéndez has been a regular reviewer for the IEEE Signal Processing Society since 2000 for several journals and international conferences, and of IET Image Processing since 2009

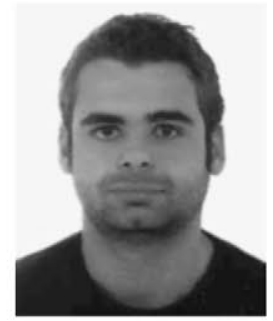

Orlando Báez has been pursuing the Telecom Engineer degree at the "Universidad Politecnica de Madrid", Madrid, Spain, since 2004.

Since October 2010, he has been working for the research group in the Visual Telecommunicacionts Applications group of the "Universidad Politécnica de Madrid". He was working in an educative innovation project for the research group in the Electronic Engineer Department (DIE) of "Universidad Politecnica de Madrid" from October 2007 to March 2008. 